\title{
O DOCENTE DE ENFERMAGEM E SUA REPRESENTAÇÃO SOBRE A FORMAÇÃO PROFISSIONAL
}

\author{
The Nursing Professor and their Representation \\ about the Professional Formation \\ La Representación del Docente de Enfermería \\ sobre su Formación Profesional
}

Juliana Rodrigues

Maria de Fátima Mantovani

\begin{abstract}
Resumo
Trata-se de uma pesquisa de natureza qualitativa, cujo objetivo foi identificar a representação do docente sobre a formação do enfermeiro. Foram entrevistados 22 enfermeiros docentes do curso de graduação em Enfermagem de duas instituições de ensino superior da cidade de Curitiba. Os preceitos éticos foram respeitados, e o projeto foi aprovado pelo Comitê do Setor de Ciências de Saúde da Universidade Federal do Paraná. As entrevistas foram gravadas e transcritas, e os relatos, analisados por meio técnica da Análise de Conteúdo. 0 tema que emergiu dos discursos foi: A representação do perfil do enfermeiro formado pela instituição. Este tema possibilitou a composição de três categorias: enfermeiro crítico-reflexivo, humanista e autônomo. Consideramos que a representação dos docentes sobre a formação do enfermeiro afasta-os cada vez mais do paradigma tradicional, aproximando-os do paradigma emergente que propõe a metodologia do aprender a aprender, e que suas representações estão ancoradas na legislação vigente e na missão da universidade: ensino, pesquisa e extensão.
\end{abstract}

Palavras-chave: Enfermagem. Prática Profissional. Ensino Superior. Educação em Enfermagem.

\section{Abstract}

It is about a research of qualitative nature, whose objective was to identify the representation of the professor on the formation of the nurse. Were interviewed 22 teaching nurses of the course of graduation in Nursing of two institutions of superior education of the city of Curitiba (Brazil). The ethics precepts were respected, and the project was approved by the Committee of the Sector of Sciences of Health of the Federal University of the Paraná (Brazil). The interviews were recorded and transcribing, and the reports, analyzed by the technique of the Analysis of Content. The theme that emerged of the speeches was: The representation of the profile of the nurse formed by the institution. This theme made possible the composition of three categories: critical-reflexive nurse, humanistic and autonomous worker. We consider that the representation of the professors about the formation of the nurse more moves them away from the traditional paradigm, approaching them of the emergent paradigm that considers the methodology of learning to learn, and that their representations are anchored in the current law and in the mission of the university: education, research and extension.

Keywords: Nursing. Professional Practice. Education, Higher. Education, Nursing.

\section{Resumen}

Tratase de una investigación de naturaleza cualitativa, cuyo objetivo fue identificar la representación del docente en la formación del enfermero. Fueron entrevistados 22 enfermeros docentes del curso de graduación en Enfermería de dos instituciones de educación superior de la ciudad de Curitiba (Brasil). Los preceptos éticos fueron respetados, y el proyecto fue aprobado por el Comité del Sector de Ciencias de Salud de la Universidad Federal del Paraná (Brasil). Las entrevistas fueron grabadas y transcriptas, y los relatos, analizados por medio de la técnica del Análisis del Contenido. El tema que emergió de los discursos fue: La representación del perfil del enfermero formado por la institución. Este tema hizo posible la composición de tres categorías: enfermero crítico-reflexivo, humanista y autónomo. Consideramos que la representación de los docentes sobre la formación del enfermero lo aleja más del paradigma tradicional, acercándole del paradigma emergente que propone la metodología del aprender a aprender, y que sus representaciones están ancladas en la ley vigente y en la misión de la universidad: educación, investigación y extensión.

Palabras clave: Enfermería. Práctica Profesional. Educación Superior. Educación en Enfermería. 
INTRODUÇÃO

A representação que o enfermeiro docente faz sobre a formação do enfermeiro é o campo de interesse deste trabalho, que está inserido na linha de pesquisa: Políticas e Práticas de Saúde, Educação e Enfermagem, do Programa de PósGraduação em Enfermagem da Universidade Federal da Paraná. Com o intuito de atender às exigências da legislação e melhorar a qualidade da formação, o debate sobre esta temática bem como a prática docente no Brasil são alvos de reflexões e questionamentos dos enfermeiros desde a última década do século $X X$ até a atualidade.

0 ensino de Enfermagem passou por várias modificações ao longo do seu desenvolvimento, e em cada uma delas percebemos o reflexo do contexto histórico e social. Refletir sobre a formação do enfermeiro é uma exigência imposta pela sociedade aos educadores, ficando evidente a necessidade de uma nova proposta para a graduação em Enfermagem, que conceba um profissional apto a atender às demandas do século XXI'. Do mesmo modo, o mundo do trabalho não admite mais a presença de profissionais limitados apenas aos aspectos da profissão, mas sim que sejam competentes e preparados para a vida, com capacidade de articular conhecimentos, com uma prática mais abrangente, sem prescindir de conhecimentos científicos da profissão $0^{2}$.

Entendemos que a prática docente é determinante para a formação profissional, e que a profissão de professor é a mais "alvissareira" entre as profissões porque a demanda de aprendizagem da sociedade vai aumentar e o "grande desafio são bons professores que saibam transformar informação em formação" (3:40).

No entanto, não conseguiremos avançar nesta prática se a atividade do docente restringir-se apenas à transmissão do conhecimento, sem a preocupação real do crescimento e amadurecimento discente. Portanto, o professor deve ser capaz de: dialogar com seus pares e com a realidade, desenvolver uma prática reflexiva, experimentar novas oportunidades, agir de forma diferente e estabelecer relações horizontais sem autoritarismo, mas com autoridade 4 . Cabe ao professor deixar que os conhecimentos e a cultura prévia de cada aluno se exteriorizem, para que seja possível que o professor aprenda com seus alunos e não apenas os veja como receptores de seus conhecimentos. Reconhecendo o discente como pessoa, o educador caminhará para um processo dialógico e de desenvolvimento mútu ${ }^{5}$.

Do mesmo modo, a educação é um desafio, pois não se resume à transmissão de informaç̃̃es, mas trata-se, sobretudo, de um processo de interação com o outro. Para tanto, o professor precisa perceber as limitações e habilidades dos sujeitos, dar foco às características individuais, à história de vida de cada um e relacioná-las com o contexto social ${ }^{6}$.

As palavras-chave que nortearão a prática desses educadores devem ser o diálogo e o comprometimento. 0 diálogo oferece ao professor e aos alunos direitos iguais de manifestação de dúvida, iniciativa e oposição de argumentos, desse modo possibilita que 0 trabalho educacional e 0 aprendizado sejam construídos em conjunto. 0 comprometimento, por sua vez, é condição para o professor se conscientizar da importância do seu papel e assumir a responsabilidade da educaçã $0^{4}$. Neste contexto de transformações da sociedade e do conhecimento,

a educação tem se modificado e vem sendo concebida segundo diferentes vertentes que privilegiam tanto a dimensão humana quanto a técnica, a emocional, a sócio-política e a cultural, levando-nos a recolocar e repensar a problemática da educação e da capacitação docente ${ }^{3: 53}$.

Desta maneira, destacamos a proposta de Delors ${ }^{7}$ para a organização da educação apresentada no Relatório para a UNESCO da Comissão Internacional sobre Educação para o século XXI. 0 autor justifica que a educação deve organizar-se nas bases de quatro pilares, ou seja, quatro aprendizagens fundamentais para poder atender as suas missões. Entre elas, o relatório destaca que à educação cabe "fazer com que todos, sem exceção, façam frutificar os seus talentos e potencialidades criativas, o que implica, por parte de cada um, a capacidade de se responsabilizar pela realização do seu projeto pessoal"::14, e para tanto "os meios utilizados abrangem as culturas e as circunstâncias mais diversas; em todos os casos, educação tem como objetivo essencial o desenvolvimento do ser humano na sua dimensão social"'7:41.

Delors comenta que, ao longo de toda a vida, estas aprendizagens serão, de alguma maneira, para cada indivíduo, os pilares do conhecimento, a saber: aprender a conhecer, aprender a fazer, aprender a viver juntos, aprender a ser.

Essa postura foi incentivada pela Lei de Diretrizes e Bases da Educação Nacional ${ }^{8}$ (LDB), nº 9394, de 20 de dezembro de 1996. Esta legislação define, entre outros, o objetivo da educação superior, que "é estimular a criação cultural, o desenvolvimento do espírito científico, do pensamento reflexivo e estimular o conhecimento dos problemas do mundo presente". Para suprir as exigências da LDB, foi aprovada a Resolução CNE/CES n. 03 de 7/11/2001, que definiu as Diretrizes Nacionais para o Curso de Graduação em Enfermagem (DCNs) ${ }^{(9)}$.

As diretrizes auxiliam no desenvolvimento de um currículo por meio das habilidades e competências. Da mesma forma, elas são a base para a formação da educação superior, do aprimoramento cultural, técnico e científico do indivíduo, assim como da flexibilização dos currículos e do estabelecimento de Projetos Pedagógicos restauradores com o objetivo de mudanças na formação profissional ${ }^{10}$.

Nesse contexto e diante do papel de "educador de saúde" desempenhado pelo profissional de enfermagem na sociedade, surge a questão norteadora deste trabalho: qual é a representação do docente sobre a formação do enfermeiro?

Consideramos que esta seja uma questão relevante para investigar como e de que forma este profissional está sendo formado e, da mesma maneira, discutir e propor sugestões para fortalecer as bases dessa prática. A busca pela resposta desta pergunta nos leva à tentativa de desvendar e de entender a configuração da prática do docente e também da formação atual do enfermeiro.

Neste sentido, destacamos que é no cotidiano da escola que surgem decisões e os momentos críticos de decisão e ação. Conseqüentemente, percebemos a importância de estudos para orientar as reflexões de problemas de conhecimento, independente do objeto em questão. Portanto, relacionando 
essas afirmações com a investigação que nos propomos, identificamos que as decisões institucionais, tanto burocráticas quanto pedagógicas, só podem ser efetivadas se refletirem a prática cotidiana de cada escola, pois é no cotidiano que as Representações Sociais (RS) nascem e retrocedem, e nele todas as coisas (automóvel, peça de vestuário, uma doença) estão acompanhadas de representações que demonstram seu pape ${ }^{11 .}$.

Portando, partimos do pressuposto que os docentes, inseridos em suas instituições de ensino, possuem uma representação do profissional formado por eles. Com base nesse pressuposto, nosso trabalho teve como objetivo: identificar a representação do docente sobre a formação do enfermeiro.

\section{METODOLOGIA}

Pesquisa de natureza qualitativa, cujo desenvolvimento foi norteado pela Teoria das Representações Sociais (RS) ${ }^{12}$. Na pesquisa qualitativa, a preocupação está voltada para 0 indivíduo e seu ambiente, ela parte do pressuposto que os conhecimentos a respeito dos indivíduos apenas serão possíveis com a descrição da experiência humana como ela é vivida e definida por seus próprios atores ${ }^{13}$.

As RS são "conjuntos dinâmicos, e seu status é o de produção de comportamentos e de relações com o meio ambiente, de uma ação que modifica aqueles e estas, e não uma reprodução desses comportamentos ou dessas relações de uma reação a um dado estímulo exterior"12:50. A RS é uma maneira de conhecimento peculiar que tem no seu ofício a produção de comportamentos e a comunicação entre as pessoas ${ }^{12}$.

Realizar uma investigação em RS é pesquisar algum fenômeno de representação que nos cerca na cultura e/ou nas práticas sociais, pois ela é elaborada no social e nele se transforma, o que caracteriza o seu dinamismo, pois ocorre no cotidiano do indivíduo, nas suas relações, com a variedade de segmentos que formam a sociedade. Ela é um elemento "modificado e modificador social", e neste trabalho tem a característica de, por meio das relações do cotidiano, coletar nos discursos a lógica das informações emitidas pelos docentes de Enfermagem ${ }^{14}$.

A pesquisa foi desenvolvida em duas universidades da cidade de Curitiba, sendo uma de caráter público, e outra, privado. A opção por estas instituiç̃̃es se justificou pelo fato de que ambas possuíam mais de dez anos de atuação na formação de enfermeiros, e já passaram por pelo menos duas modificações curriculares ocorridas no ensino de Enfermagem nos anos de 1994 e 2001.

Os sujeitos desse estudo foram 22 enfermeiros docentes do curso de graduação em Enfermagem que possuíam pelo menos um ano de atuação como professor efetivo. 0 projeto de pesquisa, após ser submetido ao Comitê de Ética em Pesquisa do Setor de Ciências da Saúde, nº 218 SM 093.05.11, e acolhido pelo Certificado de Apresentação para Apreciação Ética (CAAE), $\mathrm{n}^{\circ}$ 0043.0.091.000-05, foi analisado e aprovado.

Os dados foram coletados por meio de entrevistas no período de fevereiro a maio de 2006, e, após a autorização, as respostas foram gravadas com posterior transcrição do conteúdo na íntegra. As entrevistas foram agendadas via telefone e realizadas nas dependências das instituições de ensino, em uma sala privada. 0 instrumento de coleta de dados continha duas etapas: a primeira, com dados pessoais e profissionais para caracterizar o perfil do grupo entrevistado, e a segunda era composta por uma questão fechada e quatro questões abertas sobre o tema que foi validado antes do início da pesquisa.

Os dados foram analisados por meio da técnica da análise de conteúdo de Bardin $(A C)^{15}$ que a define como um conjunto de técnicas de análise de comunicações que visa obter indicadores que possibilitem a interferência de conhecimentos relativos às condições de produção/recepção de mensagens. $\mathrm{Na} \mathrm{RS}$, a análise de conteúdo com as entrevistas individuais são técnicas que se encontram em harmonia ${ }^{16}$.

\section{APRESENTAÇÃO E DISCUSSÃO DOS RESULTADOS}

0 grupo de docentes entrevistados foi composto por 11 sujeitos de cada instituição de ensino superior. Mais da metade do grupo está acima de quarenta anos, sendo que a faixa etária de 41 a 50 anos corresponde a quase $55 \%$ do grupo entrevistado, e, na faixa de 51 a 60 anos encontramos $32 \%$ dos docentes, a maioria com mais de 20 anos de formada. Verificamos que 5 deles possuem o título de doutor, 14, o título de mestre, sendo que 5 destes estão em processo de doutoramento e dos 3 docentes especialistas, 2 estavam cursando o mestrado. Diante deste dado, ressaltamos a Lei de Diretrizes e Bases ${ }^{7}$ de 1996, que em seu artigo 52 exige que pelo menos um terço do corpo docente deverá ter a titulação de mestres ou doutores. A análise dos dados permitiu-nos a elaboração do tema "A representação do perfil do enfermeiro formado pela instituição", que está sustentada nas categorias: críticoreflexivo, humanista e autônomo e será apresentado a seguir:

\section{Tema - A representação do perfil do enfermeiro formado pela instituição}

Diante dos discursos dos sujeitos, pudemos perceber que os profissionais formados pelos docentes são representados como: profissionais que apresentem uma postura mais crítica e reflexiva a respeito da sua atuação no mercado de trabalho, que entendam as necessidades da saúde da população e consigam posicionar-se de forma mais atuante e inovadora para a resolução de problemas. Neste sentido, cabe ao professor, em seu papel insubstituível de formulador e organizador, uma posição crítica, principalmente na educação superior, "onde a construção de conhecimento próprio e atualizado torna-se desafio essencial"17.

A categoria que trata do profissional "crítico - reflexivo" permitiu-nos a elaboração de três subcategorias: profissional crítico da realidade social, que saiba aprender - aprender e que seja pesquisador. Esta categoria significa para os docentes a formação de um ser inovador, responsável, honesto, que possui capacidade de resolver problemas e de se envolver com as questões éticas, sociais e econômicas da população. A formação técnica foi destacada como um fator importante, porém acreditam que outros fatores relacionados ao desenvolvimento do raciocínio teórico, do conhecimento científico e das questões subjetivas que permeiam a relação com o outro são indispensáveis para a formação. 
Estas características têm sua ancoragem nas Diretrizes Curriculares Nacionais ${ }^{9}$ (2001) para os cursos de graduação em Enfermagem, que direcionam o perfil do egresso, como, por exemplo: enfermeiro generalista, humanista, exercício da profissão embasada no rigor científico e intelectual, que seja capaz de intervir nos problemas de saúde-doença da população, entre outros. Os discursos a seguir exemplificam a temática.

É um pouco difícil de colocar que enfermeiro é este [...]; [...] mas o enfermeiro que eu vejo que está saindo da universidade é um enfermeiro mais crítico, reflexivo [...]; mas que seja o enfermeiro que vai atuar exercitando a sua cidadania [...] [...] a formação dele não é somente na escola, é na atuação dele junto à sociedade. (E-10)

[...] o nosso aluno está crescendo e, se ele sair e se formar com uma habilidade técnica menor, mas com uma capacidade de correr atrás das coisas [...]; [...] eu acho que esse é o diferencial, dar para o aluno esta competência de buscar, de resolver suas deficiências [...]; [...] eu acho que a competência técnica ele está preparado para aprimorar [...] [...] a gente está soltando alunos que estão correndo atrás sozinhos [...] (E-11)

Ressaltamos que o "aprender a aprender", citado pelos docentes, está contemplado dentro das características que as Diretrizes $^{9}$ vislumbram para o futuro profissional enfermeiro. Da mesma maneira, os futuros profissionais devem ser capazes de reconhecer a transitoriedade do conhecimento e buscar solução para resolver os problemas colocados em sua realidade ${ }^{18}$.

Os discursos abaixo evidenciam o empenho de alguns profissionais em formar um enfermeiro pesquisador e que, conseqüentemente, consiga fazer a integração da teoria com prática. Percebemos no discurso a seguir que esta subcategoria está intimamente relacionada com o "aprender a aprender", pois elas se entrecruzam e se estabelecem com o objetivo maior que é a produção do conhecimento na Enfermagem.

[...] nós temos estimulado a pesquisa e a extensão, $e$ os nossos alunos têm sido privilegiados, porque eu acredito que através da extensão (...) com certeza ela estimula a pesquisa e vice-versa [...] (E-2)

Todavia, para que o enfermeiro concretize as mudanças na sua prática, faz-se necessário que o futuro enfermeiro questione e pesquise o seu fazer. Para tanto, os docentes deverão reorganizar as prioridades que orientam a formação do enfermeiro, como: a ênfase da pesquisa no cotidiano, o que oxigena a prática, bem como a contextualização dos conhecimentos em relação à sociedade ${ }^{19}$. Pois, "educar pela pesquisa tem como condição essencial primeira que o profissional da educação seja pesquisador, ou seja, maneje a pesquisa como princípio científico e educativo e a tenha como atitude cotidiana"20:1-2.

A segunda categoria que emergiu dos discursos dos sujeitos foi a categoria do enfermeiro humanista, com as subcategorias: visão global para as questões éticas e sociais, respeito pelo outro e superação do déficit técnico. Para exemplificá-la, trouxemos um trecho do discurso, no qual é possível perceber que os docentes não estão mais preocupados apenas com a formação do enfermeiro voltado para as questões técnicas, preocupação que perdurou intensamente na Enfermagem, desde o seu nascimento até o final do século XX.

[...] eu tenho claro que quem passa comigo consegue visualizar que o indivíduo é um ser social, ele é um pouco mais que a biologia, que ele está inserido dentro de uma sociedade [...]; (E-12)

Verificamos nas falas do docente a tentativa de qualificar enfermeiras/os que contribuam de forma efetiva, para a implementação e/ou aprimoramento de uma proposta de atenção à saúde mais justa, visualizando o homem de forma integral, inserido na sociedade, o que atende uma proposta mais igualitária e de melhor qualidade ${ }^{21}$.

Complementando os fatos que exigiram mudanças de postura neste período de transição, salientamos novamente as DCNs ${ }^{9}$, cujo texto ressalta que a formação do enfermeiro "deve atender as necessidades sociais da saúde, com ênfase no Sistema Único de Saúde (SUS), e assegurar a integralidade da atenção e a qualidade e humanização do atendimento". Portanto, a aprendizagem para este século deve-se voltar para as "mais variadas dimensões, sejam elas educacionais, sociais, econômicas, históricas, psicológicas ou filosóficas".

Eu acho que esta estabilidade do nosso aluno foi a grande conquista que a gente teve, a gente não forma mais enfermeiros meramente técnicos, não que eu esteja desmerecendo a técnica, de forma alguma, a técnica é extremamente importante [...]. (E-11)

Minha preocupação na formação do aluno não é o conhecimento apenas da minha disciplina, mas da formação do aluno enquanto ser humano. (E-1)

Para finalizar a categoria do enfermeiro humanista, é preciso ressaltar que, no ensino superior, a formação acadêmica muitas vezes não possibilita o fortalecimento emocional dos futuros profissionais, pois em sua a maioria ela favorece os aspectos que reforçam a formação tecnicista. Humanizar o ensino a partir dos relacionamentos criados no processo de formação é uma proposta que será mais expressiva do que a de humanizar a assistência. Neste sentido, o docente tem papel de facilitador desse processo, e "a abordagem holística, no processo de formação do enfermeiro, é fundamental, considerando que a humanização do ensino é uma estratégia necessária para 0 estabelecimento de relações humanizadas"22:340.

Nas falas dos entrevistados identificamos, de maneira implícita, o aparecimento do enfermeiro autônomo, e a composição das subcategorias: enfermeiro independente e com capacidade de resolver problemas. As definições refletem o profissional formado nas bases dos quatro pilares da educação que está comprometido com as Diretrizes Curriculares ${ }^{9}$. 0 trecho do discurso a seguir reflete esta categoria: 
[...] eu tento formar um enfermeiro que deveria ser um pouco mais autônomo, que deveria acreditar nas suas potencialidades, desde que ele tivesse as ferramentas corretas, que é o conhecimento técnico-científico, conhecimento gerencial muito forte, e autonomia para o seu exercício profissional, se eu estou formando eu não sei, a gente não consegue ter uma clareza [...] (E-4)

0 discurso acima nos impõe um paradoxo em relação a esta característica, pois sabemos que o enfermeiro precisa superar barreiras e normas impostas pelos sistemas e pelas instituições de saúde, e que agir com autonomia muitas vezes vai de encontro às normas determinadas em uma sociedade em que a saúde é vista como mercadoria. É neste sentido que, muitas vezes, as ações desenvolvidas pelas enfermeiras decorrem de processos que são determinados pelo medo do outro, insegurança e conformismo diante de quem representa o poder ${ }^{23}$. A autonomia do enfermeiro "está voltada para a autonomia cotidiana (enquanto fazer), isto se distancia da autonomia ética porque representa a servidão e heteronomia" ${ }^{24}$. Os trechos a seguir exemplificam a autonomia como a capacidade de resolver problemas:

[...] esse é o diferencial, dar para o aluno esta competência de buscar de resolver suas deficiências, de se aprimorar, de encontrar soluções, de encontrar problemas de refletir sobre os problemas, de propor soluções e de ir atrás delas. (E-11)

A autonomia do enfermeiro acontece quando ele domina e cria conhecimentos sobre a sua prática e 0 seu campo, usando-os de modo adequado para o cuidado. Entretanto, além de um currículo bem estruturado, é preciso também estabelecer condições para a aprendizagem plena, pois "alunos e professores encontrarão juntos situações e lugares para explorar, conhecer e interagir como um todo", [...] para "transformar as estruturas sociais que limitam a autonomia da Enfermagem"25.

[...] atitude de uma pessoa mais autônoma, ela é mais libertária, e se paga muito caro por isso, mas eu acho que para a Enfermagem sair dessa sua visão de subserviência e de comodismo, ela tem que fazer uma atitude mais libertária, mais autônoma e pagando o preço; quanto mais conhecimento, mais envolvimento, maior responsabilidade que você mostra, e isso se traduz em competência, e dá direito de você assumir o papel com todas as vicissitudes que estão presentes [...]; (E-6)

Percebemos, por meio dos discursos dos docentes, que estes possuem com clareza a necessidade da formação de um profissional autônomo, assim como se apresentam dispostos para este propósito. No entanto, sabemos das dificuldades encontradas tanto nas instituições de ensino quanto nas assistenciais para a formação deste profissional. E questionamos: será que o mercado de trabalho tem necessidade e interesse por este enfermeiro? Ou seria melhor continuar formando profissionais alienados dos problemas sociais e econômicos, que não questionem a realidade?

É neste sentido que mencionamos que a omissão de docentes pode representar danos irreparáveis aos futuros profissionais, ou seja, se aqueles atuarem de forma alienada dificilmente irão despertar para o sentido da profissão que parece exigir uma formação mais flexível para tomar decisões ao mesmo tempo éticas e contextualizadas ${ }^{19}$. Entendemos que no ambiente da escola existem vários obstáculos para esta prática, como: a própria formação dos docentes, os campos de ensino teóricoprático, até as propostas de projetos pedagógicos. No entanto, não podemos nos paralisar por essas dificuldades. Mas, sim, buscar desenvolver no aluno o estímulo à autonomia intelectual, favorecendo o questionamento do sistema que lhes é imposto, a não-fragmentação do indivíduo e o enfrentamento de situações que envolvem o contexto saúde-doença.

\section{CONSIDERAÇÕES FINAIS}

Esta pesquisa particularizou-se por discussões e reflexões que possibilitaram considerações relevantes a respeito da identificação das representações sociais dos docentes sobre a formação do enfermeiro. Essas nos foram reveladas por meio das entrevistas, que proporcionaram a elucidação de fatores que envolvem o processo de formação do enfermeiro, bem como as situações que favorecem a contribuição do docente para realização da mesma.

Percebemos a preocupação dos sujeitos em contribuir para o desenvolvimento do compromisso e da responsabilidade, do enfermeiro cidadão e autônomo e com a capacidade de reflexão sobre a sua prática.

Portanto, acreditamos que esse estudo, ao identificar a representação do docente em relação ao perfil do formando egresso, possibilitou identificar que existe uma mudança de postura dos sujeitos. Esta cada vez mais nos remete ao paradigma emergente que propõe a metodologia do aprender a aprender e sugere aos docentes algumas reflexões como: a redução de aulas teóricas e 0 aumento do tempo para a pesquisa; favorecer o envolvimento dos alunos em trabalhos coletivos; valorizar mais a elaboração própria e dar menos peso a provas e questionários. Nesta perspectiva, o professor se torna orquestrador e articulador do processo pedagógico, faz uma parceria com o aluno e o instiga a buscar novos caminhos ${ }^{26}$. Desta maneira, também abandona, aos poucos, o paradigma da escola tradicional que prioriza a fragmentação do conhecimento e não favorece o desenvolvimento de um aluno questionador.

Sugerimos que outros estudos sejam realizados nesta área para embasar a construção de projetos pedagógicos das instituições de ensino, identificar em áreas distintas de formação as contribuições dos docentes para a formação e da mesma maneira investigar nos discursos dos enfermeiros se essas contribuições acontecem de fato na prática do ensino e da assistência. 


\section{Referências}

1. Magalhães LMT, Ide CAC. 0 ensino superior de enfermagem e 0 desafio da mudança: os referenciais de um novo processo de formação. In: Ide CAC, Domenico EBL. Ensinando e aprendendo um novo estilo de cuidar. São Paulo(SP): Atheneu; 2001.

2. Ferreira HM. A totalidade do conhecimento na enfermagem: uma abordagem curricular. Acta Paul Enferm 2003; 16(1): 56-65.

3. Demo P. Universidade: aprendizagem e avaliação. Porto Alegre(RS): Mediação; 2004.

4. Vasconcelos ML. Docência e autoridade no ensino superior: uma introdução ao debate. In: Teodoro A, Vasconcelos ML, organizadoras. Ensinar e aprender no ensino superior. São Paulo(SP): Cortez; 2003.

5. Guimarães GL. 0 perfil do enfermeiro-educador para o ensino de graduação. Esc Anna Nery Rev Enferm 2005 ago; 9(2): 225-60.

6. Peres HHC, Leite MMJ, Kurcgant P. A percepção dos docentes universitários a respeito de sua capacitação para o ensino em enfermagem. Rev Esc Enferm USP 1998; 32 (1): 52-8.

7. Delors J. Educação: um tesouro a descobrir. $6^{a}$ ed. São Paulo(SP): Cortez; 2001.

8. Lei n 9394, de 20 de dezembro de 1996. Dispõe sobre as Leis de Diretrizes e Bases da educação nacional. Diário Oficial da Republica Federativa do Brasil, Brasília (DF), 23 de dezembro 1996.

9. Resolução CNE/CES n³ de 7 de novembro de 2001. Diretrizes curriculares nacionais do curso de graduação em enfermagem. Brasília (DF); 2001.

10. Fernandes ID, etal. Diretrizes curriculares e estratégias para implantação de uma nova proposta pedagógica. Rev Esc Enferm USP 2005; 39 (4):443-49.

11. Penin S. Cotidiano e escola: a obra em construção. São Paulo(SP): Cortez; 1989.

12. Moscovici SA. A representação social da psicanálise. Rio de Janeiro(RJ): Zahar; 1978.

13. Polit DF, Hungler BP. Fundamentos da pesquisa em enfermagem. $3^{\mathrm{a} e d .}$ Porto Alegre(RS): Artes Médicas; 1995.

14. Silva MAPD. As representações sociais e as dimensões éticas. Taubaté(SP): Cabral Ed Universitária; 1998.

15. Bardin L. Análise de Conteúdo. Lisboa(P0): Ed 70; 1977.
16. Sá CP. A construção do objeto de pesquisa em representações sociais. Rio de Janeiro(RJ): EDUERJ; 1998.

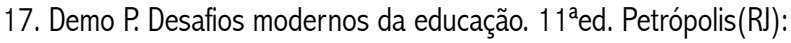
Vozes; 2001.

18. Costa HOG, et al. Novas diretrizes curriculares para o ensino de enfermagem. In: Arruda BKG. A educação profissional em saúde e a realidade social. Recife(PE): Instituto Materno Infantil de Pernambuco; 2001.

19. Sordi MRL, et al. A mudança da prática docente como determinante de um novo conceito de qualidade de ensino em enfermagem. Texto \& Contexto Enferm 1999; 8 (1): 243-56.

20. Demo P. Educar pela pesquisa. $7^{\mathrm{a} e d}$. Campinas(SP): Autores Associados; 2005.

21. Meyer DE, Kruse MHL. Acerca de diretrizes curriculares e projetos pedagógicos: um início de reflexão. Rev Bras Enferm 2003; 56 (4): 335-39.

22. Esperidião E, Munari DB. Holismo só na teoria: a trama de sentimentos do acadêmico de enfermagem sobre sua formação. Rev Esc Enferm USP 2004; 38 (3): 332-40.

23. Lunardi VL. Ampliando a compreensão do conceito de autonomia. Texto\& Contexto Enferm 1997; 6(3): 303-13.

24. Bianco MHBC. Construção da autonomia do enfermeiro no cotidiano: um estudo etnográfico sob o referencial teórico de Agnes Heller. Bauru(SP): EDUSC; 2000.

25. Angelo M. Educação em enfermagem: a busca da autonomia. Rev Esc Enferm USP 1994; 28 (1): 11-4.

26. Behrens MA. 0 paradigma emergente e a prática pedagógica. Curitiba(PR): Champagnat; 2003.

\section{Sobre as Autoras}

\section{Juliana Rodrigues}

Enfermeira. Mestre em Enfermagem pela UFPR-PR. Doutoranda pelo Programa Interunidades de Doutoramento em Enfermagem da USP-SP.

\section{Maria de Fátima Mantovani}

Enfermeira. Doutora em Enfermagem. Professora Adjunto do Departamento de Enfermagem e da Pós-Graduação da Universidade Federal do Paraná. Orientadora da Dissertação. 